\title{
ANTICUERPOS EN PERSONAL RELACIONADO CON LA CRIANZA DE AVES FRENTE A Cryptococcus neoformans, Aspergillus fumigatus $\mathbf{E}$ Histoplasma capsulatum EN CUBA
}

\section{(Antibodies against Cryptococcus neoformans, Aspergillus fumigatus and Histo- plasma capsulatum in people breeding birds, in Cuba)}

\author{
Miguel Suarez, $\mathbf{H}^{1}$; Carlos Fernandez,A, ${ }^{2}$; Elvio Alvarez, $\mathbf{M}^{1}$; \\ Geraldo Martinez, $\mathbf{M}^{2}$; José Ramón Bravo, $\mathbf{G}^{2}$ \\ 1 Centro provincial de Higiene y Epidemiología. Ciego de Avila, CUBA \\ 2. Instituto Medicina Tropical "Pedro Kouri"
}

Palabras clave: Anticuerpos, aves, Cryptococcus neoformans, Aspergillus fumigatus, Histoplasma capsulatum. Key words: Antibodies, birds, Cryptococcus neoformans, Aspergillus fumigatus, Histoplasma capsulatum.

\section{RESUMEN}

Se detectó la presencia de anticuerpos aglutinantes frente a antigenos de Cryptococcus neoformans, Aspergillus fumigatus e Histoplasma capsulatum en 387 personas vinculadas a la cria de aves (domésticas, ornamentales, palomas, trabajadores avicolas y forestales) catalogactos como de riesgo. Con fines comparativos se investigaron 64 donantes de sangre no relacionados a los grupos señalados anteriormente. A cada persona y grupo de control, se le efectuaron las técnicas serológicas de doble inmuno difusión para detectar anticuerposde Aspergillus fumigatus, Histoplasma capsulatum y la de aglutinación en tubo para Cryptococcus neoformans.

El 10,3\% de las muestras analizads en el personal expuesto presentaron anticuerpos frente a C. neoformans, mientras solo el 4,6\% los presentaron en el grupo contro $(P>0,05)$. Frente aA. fumigatus el personal expuesto. presentó solo un 0,6\% de positividad siendo negativo en el grupo control. Ambos grupos fueron negativos fiente a H.capsulatum.

\section{INTRODUCCION}

Cryptococcus neoformans, abarca dos variedades, (neoformans y gatti), las cuales se han aislado de varias fuentes ambientales tales como el suelo, ciertas especies de Eucalyptus (Myrtaceas), heces de pájaros, zumo de frutas, etc. Este microorganismo levaduriforme, se encuentra con particular frecuencia en los palomares y en el suelo contaminado con excretas no expuestas a los rayos solares. Es el agente causal de la criptococosis, una micosis cuya

\section{SUMMARY}

The presence of agglutinant antibodies against antigens of Cryptococcus neoformans, Aspergillus fumigatus and Histoplasma capsulatum was detected in 387 people engaged in the breeding of birds(domestic, ornamental, pigeons, aviculture and forest workmen) and classified as risky. In order to make a comparison, 64 blood givers not related to the above group were investigated.

Each people and control group were submitted to double immune-diffusion serological technique to detect antibodies against Aspergillus fumigatus, Histoplasma capsulatum and tube agglutination to detect Cryptococcus neoformans. The 10,3\% of samples examined in exposed personnel exhibited antibodies against C.neoformans, while only 4,6\% was detected in the control group (P>0.05). Against A.fumigatus, the exposed people revealed only a $0,6 \%$ positivity, whereas the control group was negative.

Both groups were negative against $H$. capsulatum.

via de transmisión en el hombrese atribuye a la inhalación de sus blastoconidios (1).

El género Aspergillus, es un taxon cosmopolita que incluye aproximadamente unas 200 especies (11), entre las cuales más de una decena se consideran patógenas secundarias (oportunistas) en el hombre y los animales, causando varios cuadros clínicos. A. fumigatus, $A$. flavus y $A$.niger, son una fuente importante de infección, debido a la inhalación masiva de sus conidios desde el suelo, detritus 
vegetales, granos de cereales, plantas ornamentales, ambientes hospitalarios u otros conlinados $(2,3,4,5)$.

Histoplasma capsulatum, abarca 2 variedades (capsulatum y duboisii) y su reservorio es el suelo, los excrementos de aves y la vegetación, donde vive en forma saprofítica. Su distribución en el suelo no es uniforme, dependiendo de varios factores tales como: susbstrato, humedad, $t^{\circ}$ y otros aún no bien determinados. Las excretas de aves y murcielagos favorecen su desarrollo(6).

En Cuba se han publicado reportes de casos de criptococosis y aspergilosis en investigaciones clinicas y ambientales, mientras que para la histoplasmosis se han efectuado estudios clinicos epidemiológicos $(7,8)$.Lo más importante en estos, es determinar la seroprevalencia de anticuerpos, lo cual nos permite conocer los grados de exposición en los diferentes grupos poblacionales.

El objetivo de este trabajo fue determinar la fiecuencia de anticuerpos frente a C.neoformans, $A$.fumigatus e H. capsulatum, en personal relacionado directa o indirectamente con diferentes aves, comparandolo con un grupo control (donadores de sangre) en la provincia de Ciego de Avila.

\section{MATERIALES Y METODOS}

Se estudiaron 387 personas relacionadas directa o indirectamente con la crianza de dilerentes aves, de las cuales 272 correspondian a trabajadores avicolas, 60 criadores de aves ornamentales, 15 criadores de palomas y 40 obreros forestales. Todos los investigados en el momento del estudio, ho presentaban ningúna sintomatologia clínica micótica u de otra etiología.

Todo el personal analizado, tenía en todos los grupos, entre 1 y 2 años de exposición al ambiente estudiado.

Sesenta donantes de sangre (sanos), no relacionados con los grupos anteriomente señalados, sirvió como control.

Para la búsqueda de anticuerpos (ac.) especilicos, a ambos grupos, se efectuaron las técnicas de aglutinación en tubo para C.neoformans, partiendo de una dilución de 1/2. mientras para $A$. fumigatus e H.capsulatum, se empleó la técnica de doble inmunodilusión.

Todos los antigenos usados, fueron preparados en el instituto Pedro Kouri de La Habana.

Se aplicó una prueba no paramétrica de diferencias de proporciones y el Test de Studens a nivel global y entre grupos, para comparar las medias.

\section{RESULTADOS}

La aglutinación en tubo para $C$. neoformans, entre expuestos, fue de 10,3\% (con anticuerpos), contra el 4\% observado entre donantes, siendo esta dilerencia signi- ficativa $(P=0,04)$. En el total estudiado, el $90 \%$ presentó reacción serológica positiva (Tabla 1). Con respecto a los títulos detectados en C.neoformans, predominaron los de $1 / 4$ en 18 casos y de $1 / 8$ en 11 casos respectivamente (Tabla 2).

La intensidad de la reacción fue significativamente diferente en criadores de aves ornamentales que en trabajadores avicolas, forestales y donantes. De igual forma se comportaron los criadores de palomas y los trabajadores forestales que solo difirieron de los donantes (Tabla 2).

El estudio de la detección de ac. frente a $A$. fumigatus por la técnica de doble inmunodifusión, detectó el $0,6 \%$ de ac. en la categoriáa de expuestos, en tanto que en donantes fue negativa.Esta diferencia no fue significativa (Tabla 3 ). La serologia frente a $H$. capsulatum fue negativa en ambos grupos.

Tabla 1. Frecuencia de anticuerpos frente at C. neoformans

\begin{tabular}{|c|c|c|c|}
\hline GRUPOS & Investigados & Sero + & $\%$ \\
\hline $\begin{array}{l}\text { Trabajadores } \\
\text { avicolas }\end{array}$ & 272 & 21 & 7,7 \\
\hline $\begin{array}{l}\text { Criadores aves } \\
\text { ornamentales }\end{array}$ & 60 & 8 & 13,3 \\
\hline $\begin{array}{c}\text { Trabajadores } \\
\text { forestales }\end{array}$ & 40 & 7 & 17,5 \\
\hline $\begin{array}{l}\text { Criadores de } \\
\text { palomas }\end{array}$ & 15 & 4 & 26,6 \\
\hline Subtotal Expue & lestos 287 & 40 & 10,3 \\
\hline Donantes de sa & angre 64 & 3 & 4,6 \\
\hline TOTAL & 451 & 43 & 9,0 \\
\hline
\end{tabular}

Fuente: Lab. de micología Instituto " Pedro Kouri" $\mathrm{Z}=1.441 \mathrm{P}>0,05$

Tabla 2. Títulos detectados en la aglutinación frente a $C$. neoformans

\begin{tabular}{|c|c|c|c|c|c|}
\hline \multirow[t]{2}{*}{ GRUPOS } & \multirow[t]{2}{*}{ Sero +} & \multicolumn{4}{|c|}{ TITULOS } \\
\hline & & $1 / 2$ & $1 / 4$ & $1 / 8$ & $1 / 16$ \\
\hline $\begin{array}{c}\text { Trabajadores } \\
\text { avicolas }\end{array}$ & 21 & 4 & 11 & 3 & 3 \\
\hline $\begin{array}{c}\text { Criadores aves } \\
\text { omamentales }\end{array}$ & 8 & - & l & 4 & $3 a$ \\
\hline $\begin{array}{l}\text { Trabajadores } \\
\text { forestales }\end{array}$ & 7 & - & 4 & 3 & $-b$ \\
\hline $\begin{array}{l}\text { Criadores de } \\
\text { palomas }\end{array}$ & 4 & - & - & 1 & $3 c$ \\
\hline Donantes de sangre & re 3 & 1 & 2 & - & - \\
\hline TOTAL & 43 & 5 & 18 & 11 & 9 \\
\hline
\end{tabular}


Fuente: Lab. de micología Instituto "Pedro Kouri"

Media geométrica de los expuestos 6169, donantes 3175

a- $\mathrm{P}<0,01$ en relación a avicola y donantes. $\mathrm{P}<0,05$ en

relación a forestales.

b- $\mathrm{P}<0,05$ difieren de los donantes

c- $\mathrm{P}<0,01$ en relación a avicolas, forestales y donantes.

Tabla 3. Frecuencia de anticuerpos frente a A.fumigatus

\begin{tabular}{|lccc|}
\hline GRUPOS & Investigados & Sero + & $\%$ \\
\hline $\begin{array}{l}\text { Trabajadores } \\
\text { avicolas }\end{array}$ & 272 & 2 & 0,7 \\
$\begin{array}{l}\text { Criadores aves } \\
\text { ornamentales }\end{array}$ & 60 & - & - \\
$\begin{array}{l}\text { Trabajadores } \\
\text { forestales }\end{array}$ & 40 & 1 & 2,5 \\
$\begin{array}{l}\text { Criadores de } \\
\text { palomas }\end{array}$ & 15 & - & - \\
\hline $\begin{array}{l}\text { Subtotal Expuestos } \\
\text { Donantes de sangre }\end{array}$ & 64 & 3 & 0,6 \\
TOTAL & 451 & 3 & - \\
\hline
\end{tabular}

Fuente: Lab. de micología Instituto " Pedro Kouri"

\section{DISCUSION}

La diferencia en el número de casos estudiados en la categoría de expuestos, sugiere cierta cautela en la interpretación de nuestros resultados, por lo cual deben considerarse sólo como una evaluación preliminar. Parece ser que los criadores de aves omamentales y de palomas, están más expuestos que los dedicados a la crianza de aves domésticas.

Considerando que la muestra de los donantes es muchomenor que la de los expuestos, los resultado obtenidos hacen pensar que los criadores de palomas y obreros forestales, tienen mayor riesgo de adquirir la infección que el resto. A pesar de la dilerencia de la muestra, los criadores de palomasy de avesomamentales, tienen un mayor porcentaje de seropositivos, con títulos más elevados que los criadores de aves y forestales. Esto puede asociarse, a una mayor exposición.

Los resultados obtenidos demuestran que la infección por C.neoformans, puede ser frecuente.

Aunque nuestros resultados no son comparables por las técnicas empleadas, en la provincia de Cordoba (Argentina), un estudio con criptococcina, arrojó un $31,9 \%$ de positividad, señalando los autores, que muchas personas expuestas al agente fueron asintomáticos (9) y otros grupos desarrollaron cuadros respiratorios que no fueron diagnosticados.
La prevalencia de anticuerpos a $A$. fumigatus, fue baja, detectandose seropositivos en avícolas y forestales. Se señala que las personas que por su ocupación están expuestas durante mucho tiempo a materiales contaminados con conidios de este hongo ya sea en los granos, heno, algodón, lana u otros, corren un riesgo mayor (10).

Nos llamó la atención el no haber detectado anticuepos frente a H. capsulatum, en los dos grupos analizados, ya que en la literatura nacional, se ha demostrado mediante diferentes pruebas de diagnóstico, que los grupos de mayor positividad han sido los expuestos a lugares habitados por murcielagos o gallinas (8). En la población general cubana, utilizando la prueba de la histoplasmina, el porcentaje de infección ha oscilado desde un $13,2 \%$ hasta un $14,5 \%(7,8)$.

\section{REFERENCIAS}

1. Bava, A. \& Negroni, R. (1992). Características epidemiológicas de 105 casos de criptococosis diagnosticadosen la República Argentina entre 19811990. Rev. Inst. Med. Trop. Sao Paulo 34:335-340

2. London, K.W.; Coke,A.P.; Burnic,J.P.;Lucas, G.S. \& Liu-Yin, J.A. (1994). Invasive Aspergillosis: Cluster and Sources. J. Med. Vet. Mycol. $32: 217-224$

3.Khoo, S.II.\& Denning, D.N. (1994). Invasive Aspergillosis in patients will AIDS. Clin. Infect. Dis. 19:541-548

4. Thomposon, L.; Castrillon, G.; Delgado, M.A. \& Mauricio, C. (1994). Aislamiento de diversas especies de .1spergillus de la tierra . de plantas omamentales intrahospilalarias. Rev. Med. Chile. 122:1367-1371

5. Goodlery, J.M.; Clayton, Y.M.; IIay, R.J. (1994). Envirommental sampling for aspergilly during building construction on a hospital site. I. Hosp. Inlect. 26: 27-35

6. Whent, L..J. (1992). Histoplasmosis in Indianapolis. Clin. Infect. Dis. $14: 591-599$

7. Suarć̀, M.; Fernández, C.; Estrada, A.; Cisnero, E. (1992).Reactividad a la I listoplasmina en trabajadores de granjas avícolas de provincia Ciego de Avili. Cula. Rev. Inst. Ned. Trop. Sao Paulo 34:329-333

8. Fernández, C.;Cedre, A.M.; Martinez, G.; Llop, A. \& Suárez, M. (1994). Relación entre la prucba intradennica de listoplasmina y los niveles de anticuerpos por Elisa innunodilisión. Rev. Inst. Ned. Trop. Sao Paulo. $36: 83-87$

9.Rubinstein, J.; Marticorena, B.; Masin, D.; Borricro, N.; Vega, R.; Varengo, II.\& Negroni, R. (1989). Isolation of human fungi from soil and identilication of two endemic areas of Cryptococcus neoformans and Coccidivides inmitis. Rev. Inst. Med. Trop. Sao P'aulo 31:1-6

10. Acha, P.\& Szyfres, B. ( I986). Zoonosis venfermedades transmisibles comunesal hombrev a los animales. 2da Edición. EditorialOPS, Washinton 218-220pp.

11.Raper, K.B.\& Fennell, D.I. (1965). The genus Aspergillus. Willians \& WIlliams, Baltimore 